\title{
CONSUMPTION OF ANTIBIOTICS AS SELF-MEDICATION FROM OVER-THE-COUNTER PURCHASE: AN EMPIRICAL STUDY
}

\author{
ARUNKUMAR $\mathbf{S}^{1 *}$, KUMAR CHANDAR $\mathbf{S}^{2}$, VEMBU NR $^{1}$, ABIRAMI $^{1}$ \\ ${ }^{1}$ School of Management, SASTRA University, Thanjavur - 613 401, Tamil Nadu, India. ${ }^{2}$ Department of Management Studies,Christ \\ University, Bengaluru, Karnataka, India. Email: drarunkumarprof@gmail.com
}

Received: 30 March 2017, Revised and Accepted: 19 April 2017

\section{ABSTRACT}

Objective: The primary objective of this study is to find the reasons behind the practice of self-medication (SM) by the people with over-the-counter (OTC) drugs which are usually available in all medical stores.

Methods: This article presents an empirical view of SM practice with OTC drugs. The research design of the study is descriptive, and the population of the study is customers who buy OTC drugs. The target population of this research is the common public who are all having the possibility to consume OTC drugs ever. The sampling technique used for this study is a systematic random sampling, and the sample size is 144. An instrument used for collecting data is a self-administered questionnaire and personal interview with the pharmacists. The data were analyzed using descriptive statistics.

Results: The study results that most of the OTC customers consider SM is not a good practice, even though they practice SM of antibiotics in certain circumstances, due to reasons such as time-saving, convenience, cost saving, avoid waiting time to consult a doctor, easy and quick availability of antibiotics in neighbourhood drug stores, etc.

Conclusion: The study concludes the reasons behind the SM practice and some remedies to overcome OTC drug-related problems from SM.

Keywords: Self-medication, Over-the-counter drugs, Antibiotics, Self-treatment.

(C) 2017 The Authors. Published by Innovare Academic Sciences Pvt Ltd. This is an open access article under the CC BY license (http://creativecommons. org/licenses/by/4. 0/) DOI: http://dx.doi.org/10.22159/ajpcr.2017.v10i7.18793

\section{INTRODUCTION}

Self-medication (SM) is an irrational use of the drugs, and it is a form of self-care or self-treatment without doctor's advice and prescription. According to the World Health Organization, the definition of SM is "the use of medicinal products by the consumer to treat self-recognized disorders or symptoms or the intermittent or continued use of medication prescribed by a physician for chronic or recurring diseases or symptoms." It involves the consumption of medicinal products such as tablets, capsules, tonic to treat themselves for their medicinal needs or clinical needs, but actually, it cures certain symptoms and disorders. People usually go with SM is for urge of self-care, feeling of sympathy toward family members while sickness, lack of health services, poverty, ignorance, extensive advertisement, convenient, cost saving, easy availability in nearby pharmacies, need not wait for physician's appointment.

It is mainly due to lack of access to health care, and primary healthcare centers, easy, and adequate availability of over-the-counter (OTC) drugs to market and poor drug regulatory practices in those countries. The recent development of the pharmaceutical companies contributes to a widespread availability of OTC medicine; it would lead to abuse and misuse of those drugs. SM, particularly with antibiotics has been widely reported to lead the WHO to call attention to the dangers of SM as a cause of antibiotic resistance. For SM people normally buying medicinal products private drug store or pharmacies not showing interest toward the Government Hospital, Primary Health Centers. The objectives of this study are to find out the reasons for purchasing antibiotics OTC for their clinical needs as a SM practice, to understand the demographic profile of OTC customers, to study the purchase behavior of OTC customers. The rationale of the research tries to find out the consumer perception and purchase behavior of OTC drugs. The novelty of this study is, while collecting data from various research articles we found that only a few articles are dealing with purchase behavior of antibiotics OTC, so the researcher decided to undertake the study on OTC drugs, especially about consumer perception and purchase behavior of antibiotic medicines OTC for their SM practice, also we personally interviewed some pharmacists to enrich the quality of the study. Collected reviews for better understanding are as follows:

Khan, 2016 [1] in their research they studied about the quality and affordability of amoxicillin generic products in a patient's concern. It explores the quality of generic amoxicillin products and associated price along with their burden on patients was evaluated. The researcher concludes that situation demands the evidence of safety before approval and thereafter too. However, the situation may become worse if the price and quality could not be controlled. Thus, Indian drug regulatory bodies need to be entreated to counter these critical issues.

Roulet, 2012 [3], the study carried out to develop the questionnaire for obtaining a complete medication history by documenting SM history in adult patients admitted to a medical emergency department. The study reveals the details of SM practice among adults and their behavior. The study also states that there are some difficulties in collecting the data from patients, especially with close-ended questions; hence, the research paper consists of the observation of patient behavior and which concludes that implementing tools that facilitate SM history collection should enhance the recognition of iatrogenic conditions related to SM and more largely provide support to public health efforts and research programs on this issue.

Mayura and Kale, 2015 [4] in their research they studied the role of antioxidants and nutrition in oxidative stress, and the researcher attempt to generate interest in the scientific fraternity of their immense potential in preventing and treating several common diseases, the study includes the role of nutrition.

Saleem et al. 2011 [5], the study is to obtain baseline data on SM with OTC drugs in Perinthalmanna also to gain more information on the factors influencing SM practice with OTC drugs and to identify any association 
of SM with demographic factors. Data were collected through face-toface-structured interview of respondents in the pharmacy. The study also states that although SM is difficult to eliminate, interventions can be made to discourage the practice and ensure safe usage of drugs. The intervention will require better patient education of the public and health professionals to avoid the irrational use of drugs. The researcher concludes that the prevalence of SM practice with OTC drugs in Perinthalmanna, Kerala is high.

Mythri, 2016 [6], the researcher employed a questionnaire-based study, and the data were collected from various groups of respondents such as medical students, pharmacies, nursing students, teachers, parents, etc. This study focuses on the overall concept of selfmedication practice and to identify whether the practice is a hype or hope for humans and the study concludes that the SM practice is growing in all sorts of people.

Khan, 2017 [8] in their research they studied about a treatment pattern and its outcomes of positioning cases in a tertiary care and government district hospital. The objective is to identify the treatment pattern and outcomes of poisoning cases admitted to the Basaveshwara Medical College, Hospital and Research Centre and Government District Hospital and to determine the type of poison cases. Totally, 100 cases were enrolled in this study of data collection, and the research is concluded that younger age adults constituted a significant percentage of the subjects. It is essential, therefore, to propose policies that can terminate the free trade of poisonous pesticides and to create awareness and periodically counsel the vulnerable group of the population.

Jain 2011 [10] in their research studied about the concept of SM. The research study presents the information about the reasons behind the SM or self-treatment practice. The researcher categorizes the complaints that can be treated with antibiotics and lists the drugs which come under antibiotics; the researcher also deals with the role and duties of pharmacists while prescribing medicines OTC, the reasons behind the parents while treating their children with OTC drugs and the merits and demerits of this SM practice.

Gupta, 2014 [11] reveals in their study that by focusing on the overall review of the prevalence of SM, and the research was conducted in Indonesia, North Nigeria, Ghana (Accra), North India, with the focus of medicines preferred by doctors/pharmacist for the complaints in these regions. It includes the reasons of SM practice, merits, and demerits, etc. The researcher concludes the study that the practice of SM and its reasons are growing day-by-day and even medical students have an inclination to self-medicate.

Aqeel, 2014 [12] research deals with the evaluation of the prevalence and associated factors of self-medication among urban and rural population of Islamabad, Pakistan. This study shows an association between self-medication and gender, education and urban and rural population significantly differ on the most common reason, source of drug, symptoms.

Surendran, 2014 [7] this study is to assess the self-medication practice and related knowledge among nursing students was conducted among 200 subjects using descriptive design. It concludes that the prevalence of self-medication among nursing students was high and a significant number of students are unaware of the adverse effects of the medication that they themselves take and suggest to others. Therefore, potential problems of self-medication should be emphasized to the students.

Lamikanra, 2012 [2] studied about the prevalence of self-medication with antibiotics and anti-malarial among university students in southwestern Nigeria and evaluate the factors associated with self-medication. The study revealed that age, gender and students' level in the university influenced self-medication practices. The use of antibiotics in self-medication calls for urgent health policy intervention.
Mehta, 2013 [9] in this report, it reveals about the people's attitude, knowledge, practices of self-medication and its implications in Ilala Municipal, Dares Salaam. The study reveals that there is a high prevalence of self -medication amongst the care takers for under five years old children and in the general population of Ukonga Ward. Thus, females are nearly 2 times more likely to self- medicate their children than the males. Generally, there is lack of knowledge about the practice of self-medication itself and its implications. There is a high prevalence of self -medication amongst the care takers for under five years old children and in the general population of Ukonga Ward. Thus, females are nearly 2 times more likely to self- medicate their children than the males. Generally, there is lack of knowledge about the practice of selfmedication itself and its implications.

WHO (2000) g uidelines for the Regulatory Assessment of medicinal Products for Use in Self-Medication. Geneva emphasizes on the need to use OTC drugs responsibly as inappropriate use predisposes one to deleterious implications.

\section{METHODS}

The research design of the study is descriptive, and the population of the study is customers who buy OTC drugs. The sampling frame constitutes

Table 1: Demographic profiles of the OTC customers

\begin{tabular}{ll}
\hline Variables & Respondents (\%) \\
\hline Gender & \\
Male & $57(46.7)$ \\
Female & $65(53.3)$ \\
Marital status & \\
Unmarried & $40(32.8)$ \\
Married & $82(67.2)$ \\
Age & \\
20-30 & $25(20.5)$ \\
$31-40$ & $31(25.4)$ \\
$41-50$ & $66(54.1)$ \\
Education & \\
SSLC & $11(9)$ \\
HSC & $20(16.4)$ \\
UG & $66(54.1)$ \\
PG & $25(20.5)$ \\
Income & \\
10,000-15,000 & $11(9)$ \\
15,000-20,000 & $51(41.8)$ \\
20,000 and above & $60(49.2)$ \\
Occupation & \\
Private & $110(90.2)$ \\
Public & 0 \\
Own business & $12(9.8)$ \\
\hline
\end{tabular}

OTC: Over-the-counter

Table 2: Treated with SM (antibiotics) in the past 1 year - count/ times

\begin{tabular}{ll}
\hline Count & Number of respondents (\%) \\
\hline$<5$ times & $102(83.6)$ \\
$5-10$ times & $20(16.4)$ \\
Total & $122(100.0)$ \\
\hline
\end{tabular}

SM: Self-medication

Table 3: Reasons of SM with antibiotics

\begin{tabular}{ll}
\hline Reasons & Number of respondents (\%) \\
\hline Cost saving & $33(27.0)$ \\
Convenience & $74(60.7)$ \\
Others & $15(12.3)$ \\
Total & $122(100.0)$ \\
\hline
\end{tabular}

SM: Self-medication 
the customers who visit pharmacies located within the Thanjavur city and then Thanjavur city is categorized into North, West, East, and South for the systematic sample selection procedure. From each of these, strata six medical shops were identified randomly and using systematic random sampling every fourth customer coming out of the cash counter from the medical shop has been interviewed, and the questionnaire got self-administered to the total 144 respondents. However, only 122 valid responses of data got obtained. The questionnaire was developed with the help of secondary literature, and literature matrix technique was used to frame the construct with respective variables. The framed construct was content validated with the help of academicians, researchers, and few OTC customers. The data were analyzed with the help of version 16 SPSS software.

\section{RESULTS AND DISCUSSION}

From the Table 1, it is inferred that demographic variable such as gender, age, marital status, income, education, and occupation of the respondents from the target population. Compare to male, female respondents, i.e., $53.3 \%$ of them practice SM. Unmarried respondents are higher than married respondents i.e., $67.2 \% .54 .1 \%$ of respondents belong to the age category between 41 and 50 years practice SM. $54.1 \%$ of graduates do SM. It also reveals that higher income group respondents are practicing SM i.e., 49.2\%. Private sector respondents are in more number who is practicing SM (90.2\%).

Table 4: Antibiotics used for which complaints

\begin{tabular}{ll}
\hline Symptoms & Number of respondents (\%) \\
\hline Cold symptoms & $72(59.0)$ \\
Aches and pains & $15(12.3)$ \\
Fever & $10(8.2)$ \\
Vomiting and diarrhea & $25(20.5)$ \\
Total & $122(100.0)$ \\
\hline
\end{tabular}

Table 5: Selection of antibiotics

\begin{tabular}{ll}
\hline Selection of antibiotics & Number of respondents (\%) \\
\hline Recommendation by pharmacists & $81(66.4)$ \\
My own experience & $16(13.1)$ \\
Previous doctor's prescription & $25(20.5)$ \\
Total & $122(100.0)$ \\
\hline
\end{tabular}

Table 6: Factors considered in selecting antibiotics

\begin{tabular}{ll}
\hline Factors & Number of respondents (\%) \\
\hline Brand name of antibiotics & $27(22.1)$ \\
Price of antibiotics & $46(37.7)$ \\
Chemical composition & $49(40.2)$ \\
Total & $122(100.0)$ \\
\hline
\end{tabular}

Table 7: Place of obtaining antibiotics for SM

\begin{tabular}{ll}
\hline Place of obtaining & Number of respondents (\%) \\
\hline Pharmacist & $102(83.6)$ \\
Leftover from previous prescription & $20(16.4)$ \\
Total & $122(100.0)$ \\
\hline
\end{tabular}

Table 8: Check the instructions come with the package insert of antibiotics for self-treatment

\begin{tabular}{ll}
\hline Verify instruction & Number of respondents (\%) \\
\hline Yes, always & $36(29.5)$ \\
Yes, sometimes & $65(53.3)$ \\
Never & $21(17.2)$ \\
Total & $122(100.0)$ \\
\hline
\end{tabular}

From the Table 2, it is inferred that $83.6 \%$ respondents are self-treated with antibiotics for $<5$ times in the past 1 year and only $16.4 \%$ of them are taken more than 5 times in a year.

From the Table 3, it is inferred that $60.7 \%$ of the respondents practice SM for their convenience and $27 \%$ of them chose SM for cost saving purpose, $15 \%$ of the respondents gave other reasons such as timesaving, not to wait in clinic to consult doctor and having adjacent neighborhood medical shops.

From the Table 4, it is inferred that more than $50 \%$ of the respondent's practice SM, especially with antibiotics for cold, cough, sore throat, etc. $20.5 \%$ respondents are doing SM for complaints such as vomiting and diarrhea and $12.3 \%$ of respondents is doing SM for relief from aches and pains.

From the Table 5, it is inferred that $66.4 \%$ of the targeted population is consuming antibiotics from the recommendations of pharmacists, $20.5 \%$ of the respondents are using previous doctor's prescription, and $13.1 \%$ of the respondents chose by their own previous experiences.

From the Table 6, it is inferred that the $40.2 \%$ of the respondents select antibiotics based on the chemical composition, $37.7 \%$ based on the price of the antibiotics, $22.1 \%$ based on the brand name of the antibiotics. Hence, we know that most of the respondents from target population are aware of adverse reactions of taking antibiotics.

The Table 7 shows that $83.6 \%$ of the respondents are getting antibiotics OTC. The reason behind this is the easy and quick availability of drug

Table 9: Level of understanding the instructions

\begin{tabular}{ll}
\hline Level of understanding & Number of respondents (\%) \\
\hline Fully understood & $56(45.9)$ \\
Partly understood & $45(36.9)$ \\
Did not understand at all & $21(17.2)$ \\
Total & $122(100.0)$ \\
\hline
\end{tabular}

Table 10: Know the dosage of antibiotics

\begin{tabular}{ll}
\hline Dosage & $\begin{array}{l}\text { Number of } \\
\text { respondents (\%) }\end{array}$ \\
\hline By consulting a doctor & $41(33.6)$ \\
By consulting a pharmacist & $46(37.7)$ \\
By consulting family members/friends & $20(16.4)$ \\
From my previous experience & $15(12.3)$ \\
Total & $122(100.0)$ \\
\hline
\end{tabular}

Table 11: Changing the dosage of antibiotics deliberately during the course of treatment

\begin{tabular}{ll}
\hline Change od Dosage & Number of respondents (\%) \\
\hline Yes, always & $37(30.3)$ \\
Yes, sometimes & $75(61.5)$ \\
Never & $10(8.2)$ \\
Total & $122(100.0)$ \\
\hline
\end{tabular}

Table 12: Reason for changing the dosage of antibiotics during the course of treatment

\begin{tabular}{ll}
\hline Reason for changing dosage & Number of respondents (\%) \\
\hline Improving conditions & $40(32.8)$ \\
Worsening conditions & $82(67.2)$ \\
Total & $122(100.0)$ \\
\hline
\end{tabular}


Table 13: Reason for switching antibiotics during the course of treatment

\begin{tabular}{ll}
\hline Reason for switching & $\begin{array}{l}\text { Number of } \\
\text { respondents (\%) }\end{array}$ \\
\hline $\begin{array}{l}\text { The former antibiotics does not cure the } \\
\text { symptoms }\end{array}$ & $56(45.9)$ \\
The former antibiotics ran out & $10(8.2)$ \\
The latter one was cheaper & $21(17.2)$ \\
To reduce adverse reactions & $35(28.7)$ \\
Total & $122(100.0)$ \\
\hline
\end{tabular}

Table 14: Normally stop taking antibiotics

\begin{tabular}{ll}
\hline Stop taking antibiotics & $\begin{array}{l}\text { Number of } \\
\text { respondents (\%) }\end{array}$ \\
\hline After a few days regardless of the outcome & $46(37.7)$ \\
After symptoms disappeared & $30(24.6)$ \\
A few days after the recovery & $10(8.2)$ \\
At the completion of the course & $26(21.3)$ \\
After consulting a doctor/pharmacist & $10(8.2)$ \\
Total & $122(100.0)$ \\
\hline
\end{tabular}

Table 15: Had an adverse reaction by taking antibiotics as SM

\begin{tabular}{ll}
\hline Had any adverse reaction & Number of respondents (\%) \\
\hline Yes & $60(49.2)$ \\
No & $62(50.8)$ \\
Total & $122(100.0)$ \\
\hline
\end{tabular}

SM: Self-medication

Table 16: Actions are taken for adverse reaction

\begin{tabular}{ll}
\hline Action for adverse reaction & Number of respondents (\%) \\
\hline Stopped taking antibiotics & $20(16.4)$ \\
Consulted pharmacy staff & $5(4.1)$ \\
Consulted a doctor & $97(79.5)$ \\
Total & $122(100.0)$ \\
\hline
\end{tabular}

Table 17: Opinion about SM

\begin{tabular}{ll}
\hline Opinion & Number of respondents (\%) \\
\hline Good practice & $11(9.0)$ \\
Acceptable practice & $68(55.7)$ \\
Not acceptable practice & $43(35.2)$ \\
Total & $122(100.0)$ \\
\hline
\end{tabular}

SM: Self-medication

Table 18: Common adverse reaction by taking antibiotics

\begin{tabular}{ll}
\hline Common adverse reaction & Number of respondents (\%) \\
\hline Vomiting & $26(21.3)$ \\
Diarrhea & $81(66.4)$ \\
Rashes & $15(12.3)$ \\
Total & $122(100.0)$ \\
\hline
\end{tabular}

stores, and rest of the $16.4 \%$ are using the previous prescription from the doctors in earlier complaints.

Table 8 shows that more than half of the targeted population, i.e., $53.3 \%$ check the instructions sometimes which comes with the package of antibiotic drugs, $29.5 \%$ always check the instructions, and $17.2 \%$ are never check the instructions in the package.
Table 9 shows that $45.9 \%$ of the respondents fully understood the instructions given in the package, $36.9 \%$ are partially understood the instructions, and $17.2 \%$ of the respondents did not understand the instructions in the package.

The Table 10 clearly shows that $37.7 \%$ respondents know the dosage from the pharmacist, $33.6 \%$ of the respondents know the dosage by consulting a doctor, $16.4 \%$ of the respondents know the dosage of antibiotics by consulting with the family members, and friends and $12.3 \%$ get to know the dosage by their own previous experience.

Table 11 clearly shows that $30.3 \%$ of the respondents are always changing the dosage of antibiotics deliberately during treatment, then $61.5 \%$ of them sometimes change the dosage, and $8.2 \%$ of the respondents never change the dosage during treatment.

From the Table 12, it is inferred that $67.2 \%$ of the respondents change the dosage of antibiotics during treatment due to worsening of a health condition, then $32.8 \%$ of the respondents change antibiotics dosage due to improving health condition.

From Table 13, it is inferred that $45.9 \%$ of the respondents switching the antibiotics to different antibiotics since the former antibiotics does cure the symptoms, $28.7 \%$ of the respondents switch antibiotics to reduce adverse reactions, $17.2 \%$ of them switch when the latter antibiotics are cheaper than others, and $8.2 \%$ of the respondents switch when the former antibiotics ran out of the market.

From Table 14, it is inferred that $37.7 \%$ of the respondents stop taking antibiotics after few days, regardless of the outcome, $24.6 \%$ of the respondents stop taking antibiotics after the symptoms disappeared, $21.3 \%$ of the respondents stop taking after the completion of the course of treatment, $8.2 \%$ of them stop taking after a few days of recovery, and $8.2 \%$ of the respondents stop taking after consulting a doctor/ pharmacist.

From Table 15, it is inferred that there is no major difference in the number of respondents who already had an adverse reaction by taking antibiotics as an SM practice.

From Table 16, it is inferred that $79.4 \%$ of the respondents immediately consult a doctor when they had adverse reactions because of taking antibiotics, $16.4 \%$ of the respondents stop taking the antibiotics, and only $4.1 \%$ of them consult a pharmacy staff. It reveals that most of the respondents from the targeted population are having the awareness and knowledge of consulting a doctor when they had any adverse reaction of taking antibiotics as an SM practice.

Table 17 clearly shows that $55.7 \%$ of the respondents gave their opinion as SM is an acceptable practice, $35.2 \%$ respondents gave their opinion as it is not an acceptable practice and finally $9 \%$ of the respondents from the targeted population gave their opinion as SM is a good practice.

Table 18 clearly shows that $66.4 \%$ of the respondents had diarrhea as an adverse reaction by taking antibiotics, $21.3 \%$ of them had to vomit as an adverse reaction and $12.3 \%$ of the respondents had rashes as an adverse reaction because of taking antibiotics as an SM practice.

The study concludes that most of the OTC customers consider SM is not a good practice even though they practice SM of antibiotics in certain circumstances, due to reasons such as time-saving, convenience, cost saving, avoid waiting time to consult doctor, easy, and quick availability of antibiotics in neighborhood drug stores, etc. The study also highlights the popularity of SM is due to the helping hands of pharmacists working in the physical drug stores whereby these practices fulfills the immediate clinical needs of semi-urban and rural areas. The SM practices also manage the pressure of scarcity of healthcare personnel. 


\section{CONCLUSION AND SUGGESTION}

Hence, the study reveals that SM may lead to misuse of drugs, over consumption regardless the dosage, sometimes leads to adverse reactions, for instance, cough syrups are mostly used even by adults to sleep and which may lead to addiction. To overcome the issues:

- Pharmacists should insist not to provide more antibiotics regardless of dosage for his business growth. He should sell antibiotics only by receiving a doctor's prescription from the patients

- Regulatory measures to be taken by the relevant authorities such as inspection of drug stores and review the sales report of drug stores

- Ministry of Health, India should increase the number of health-care workers to meet the clinical needs in semi-urban and rural areas.

\section{REFERENCES}

1. Khan RK. Quality and affordability of amoxicillin generic products: A patient concern. Int J Pharm Pharm Sci 2016;8(1):386-90.

2. Lamikanra KO. A study of the prevalence of self-medication practice among university students in Southwestern Nigeria. Trop J Pharm Res 2012;11(4):683-9.

3. Roulet NA. A questionnaire to document self-medication history in adult patients. France: Wiley Online Library; 2012.
4. Mayura A, Kale SM. The role of antioxidants and nutrition in oxidative stress: A review. Int J Appl Pharm 2015;7(1):1-4

5. Saleem TK, Dilip CS, Azeem AK. Self-medication with over the counter drugs: A questionnaire based study. Sch Res Libr Pharm Lett 2011;3(1):91-8.

6. Mythri H. Research on self-medication: A hype or a hope? A literature review. Asian Pharm Clin Res 2016;9(6): 28-31.

7. Surendran SP. Self-medication practice and related knowledge among students of selected nursing institutions, Ernakulam. Int J Pharm Med Biol Sci 2014;3(3):127-30

8. Khan DC. Study on treatment pattern and outcomes of poisoning cases in a tertiary. Int J Pharm Pharm Sci 2017;9(4):193-7.

9. Mehta SS. Knowledge, attitude, and practice of self-medication among medical students. J Nurs Health Sci 2015;4(1):89-96.

10. Jain RM. The concept of self-medication: A review. Int J Pharm Biol Arch 2011;2(3):831-6.

11. Gupta PG. Prevalence of self medication: A review. J Manag Sci Technol 2014;2(1):35-40.

12. Aqeel T, Shabbir A, Basharat H, Bukhari M, Mobin S, Shahid H, et al. Prevalence of self-medication among urban and rural population of Islamabad, Pakistan. Trop J Pharm Res 2014;13(4):627-33.

13. WHO. Guidelines for the Regulatory Assessment of medicinal Products for Use in Self-Medication. Geneva: WHO; 2000. Available from: http://www.apps.who.int/medicinedocs/pdf/s2218e/s2218e.pdf. 